\title{
REPLY TO THE AUTHORS: Re: Endourologic strategies for a minimally invasive management of urinary tract stones in patients with urinary diversion
}

FangLing Zhong ${ }^{1}$, Gurioli Alberto ${ }^{2}$, GuangMing Chen ${ }^{1}$, Wei Zhu ${ }^{1}$, FuCai Tang ${ }^{1}$, Guohua Zeng ${ }^{1}$, Ming Lei ${ }^{1}$

${ }^{1}$ Department of Urology, Minimally Invasive Surgery Center, the First Affiliated Hospital of Guangzhou Medical University, Guangdong Key Laboratory of Urology, Guangzhou, China; ${ }^{2}$ Department of Urology, Turin University of Studies, Turin, Italy

To the editor,

We appreciated the valuable comments on our recent published article in the International Braz J Urol $(1,2)$. We agree with the commentary, to our knowledge, these studies have shown that the complicated patients with lower tract stone were treated by endoscopic management.

In patients with reservoir stone after urinary diversion, stone management present unique challenges. In our research, 3 patients with reservoir stones following urinary diversion were treated by transurethral neo-bladder lithotripsy, and one patient had $6 \mathrm{~mm}$ residual stone postoperatively and received subsequently conservative watching treatment (2). Recently, percutaneous pouch access and laparoscopic techniques to facilitate the treatment of lower tract stones has become popular $(3,4)$.

With the advancement of equipments and increasing experience, the surgical management of urolithiasis in patients with urinary diversion are varied, individualized consideration and comprehensive evaluation must be taken into account, which depending upon diversion type, patient fitness, stone size, stone location, available resource and surgeon experience $(5,6)$.

\section{CONFLICT OF INTEREST}

None declared. 


\section{REFERENCES}

1. Pina IM, Floyd MS Jr, Stubington SR. Re: Endourologic strategies for a minimally invasive management of urinary tract stones in patients with urinary diversion. Int Braz J Urol. 2018;44(2):[Ahead of Print].

2. Zhong F, Alberto G, Chen G, Zhu W, Tang F, Zeng G, Lei M. Endourologic strategies for a minimally invasive management of urinary tract stones in patients with urinary diversion. Int Braz J Urol. 2018;44:75-80.

3. L'Esperance JO, Sung J, Marguet C, L'Esperance A, Albala DM. The surgical management of stones in patients with urinary diversions. Curr Opin Urol. 2004;14:129-34.

Submitted for publication:

March 29, 2018

Accepted after revision:

March 30, 2018

Published as Ahead of Print:

April 10, 2018
4. Okhunov Z, Duty B, Smith AD, Okeke Z. Management of urolithiasis in patients after urinary diversions. BJU Int. 2011;108:330-6.

5. Seth JH, Promponas J, Hadjipavlou M, Anjum F, Sriprasad S. Urolithiasis following urinary diversion. Urolithiasis. 2016;44:383-8.

6. Zhong W, Yang B, He F, Wang L, Swami S, Zeng G. Surgical management of urolithiasis in patients after urinary diversion. PLoS One. 2014;9(10):e111371.

Correspondence address:

Ming Lei, MD

Department of Urology

Minimally Invasive Surgery Center, the First Affiliated Hospital of Guangzhou Medical Univ.

Guangdong Key Laboratory of Urology Guangzhou, 510230, China

Telephone: +86 020 3429-4145

E-mail: 1mlm_leiming@126.com

ARTICLE INFO

Int Braz J Urol. 2018; 44: 848-9 